\title{
How Quickly Should Entrepreneurs Pursue Opportunities? Insights from the Mining Industry
}

\author{
Dean Shepherd (Notre Dame University)
}

KEYWORDS: Mining, Quarrying, Oil, Gas, Entrepreneurship, Management.

History is filled with stories about people who lament that they passed too quickly on an opportunity that later hit it big, or that stayed too long with a losing enterprise. Entrepreneurs, who are often considering many opportunities at a time, must make both quick and shrewd decisions.

In few other industries are the stakes higher than in mineral mining, where the earliest decision to develop a mine becomes a huge commitment in resources and much harder to undo later. We studied how quickly Australian mining companies made decisions to explore or not explore a mine, and how this affected their decision-making once the exploration got underway. My study co-authored by Rene Bakker - published in the Academy of Management Journal in February 2017-reports that companies that made quick decisions at the earliest phase were not necessarily speedy decision makers once the project got underway -- in fact they are often much slower to pull the plug. They were also slower decision-makers overall.

"Using unique data on 3,269 mineral exploration ventures in the Australian mining industry, we find that firms with a higher degree of attention toward earlierstage exploration activities are quicker to abandon potential opportunities in early development but slower to do so later, and that such firms are also slower to advance on potential opportunities at all stages compared to firms that focus their attention differently," the article concludes.

In mining, early decisions are critical because firms must decide whether or not to explore before the competition moves in. Companies that bet on the right mine at the right time enjoy a big upside; but the cost of getting in or pulling out becomes higher as the phases of testing and exploration commence. Entrepreneurs and other kinds of companies also face early decisions on whether to pursue a certain market or develop an innovation before the competition.

While our research didn't focus on other industries, we see that entrepreneurship often involves the same three critical phases that mining companies - and many other types of enterprises -- know well:

- Prospecting involves grassroots exploration of opportunities, whether it's an unexplored piece of land, a new technology or an unmet market need. This phase is not unique to the mining industry; other research (Rosenkopf \& Nerkar, 2001; Brown \& Eisenhardt, 1997; McGrath, 1999) discusses how other types of companies might look for opportunities far beyond the realm of their core product - by building experimental products, conducting exploratory research and development, then deciding whether it's worth moving to the next stage.

- Developing explores the opportunity's feasibility and desirability more deeply and requires more time and money. Mining companies must weigh the cost of the development against the potential riches from the fully developed mine and decide if it's worth it. Some things to consider are potential market demand (Chrisman and McMullan, 2000), production costs (Ardichvili et al, 2003) and the value the mine might create in the future (Ardichvili et al, 2003) - all factors that other industries beyond mining must consider too.

- Exploiting is the third and most resourceintensive phase involves actually building the operations needed to make the opportunity a reality. More than 90 percent of the mining opportunities never reach the third phase. 
"Exploitation also involves a different repertoire of operating procedures than that of the other stages," the study notes. "This is also true in the case of any radically different new product as effective exploitation often involves establishing efficient production systems, instituting new routines, and investing in scale for efficient production." (Dobrev \& Carroll, 2003.)

Most of the companies that we studied have developed decision-making abilities in only one domain. Three things contribute to quick and accurate decisions -experience, standard operating procedures and confidence - and most companies don't have all these strengths in all phases of a project.

We also saw a connection between market forces and decision-making speed, especially at the earliest "prospecting" stage. Pointing to work by other researchers, we hypothesized that in a dynamic environment, "previously developed knowledge, experience and confidence are less likely to be applicable to current decisions (Bakker \& Knoben, 2015). As a consequence, when dynamism is high, firms with a higher degree of attention towards earlierstage exploration activities are less able to capitalize on their stock of knowledge, experience and confidence (Judge \& Miller, 1991; Forbes, 2005.)" Our research showed that dynamic markets lengthened the decisionmaking process at the prospecting stage, but not at the developing and exploiting stages.

\section{The Takeaway}

As the study notes: "A takeaway from our findings is that managers, by focusing their attention toward certain types of decisions, can learn how to identify early signs that a potential opportunity does not show promise and terminate it quickly, or alternatively, how to look for signs of potential and push the potential opportunity through the advancement process quickly. Early decisions to terminate free up resources for prospecting, developing and exploring other potential opportunities, whereas quick advancements limit costs and maximize upside potential. Managers that manage to focus their attention toward areas that are most relevant to the business' future are more likely to develop experience, standard operating procedures, and confidence and hence be quicker to make 'pull the plug' and 'take the plunge' decisions in those areas that matter most to them."

\section{EIX Editor Commentaries}

Mining is a great metaphor for entrepreneurship in general. Mining involves exploring opportunities and deciding where to dig in, and the financial costs of picking the wrong opportunity are great. Getting in early, and deciding whether to dig in or pass on an opportunity, can be critical, especially for unique ideas with no competition yet. This research suggests that speed is important.

This research also suggests that entrepreneurs should understand where they have the most confidence and experience at decision-making and surround themselves with others who have more experience and confidence in the other phases...and then trust their judgment for those critical decisions.

\section{-- Jon Eckhardt}

There is a developing literature on the speed of decisionmaking, the architecture of the enterprise, and speed of growth. One practitioner example comes to mind in this area. Entrepreneurs Reid Hoffman and Chris Yeh outline and elaborate on the methods and approaches used by recent high-growth companies (e.g. Linkedln, Dropbox, Airbnb), that offers some evidence for the author's hypothesis on the relationship between fast decision making and rapid business growth. (forthcoming book: Blitzscaling: Unlocking Silicon Valley's Secrets for Building Multi-Billion-Dollar Companies, http://www.blitzscaling.com (http://www.blitzscaling.com) ).

--Nicholas Vitalari

\section{Explore the Research}

Bakker, Rene and Shepherd, Dean: "Pull the Plug or Take the Plunge: Multiple Opportunities and the Speed of Venturing Decisions in the Australian Mining Industry," Academy of Management Journal, vol. 60 no. 1, pp. 130-155, February 2017. 